\title{
PENGELOLAAN KREDIT DALAM UPAYA MENINGKATAN LIKUIDITAS PADA BANK NAGARI PADANG
}

\author{
Ria Irwan, Elva Dona \\ Akademi Keuangan dan Perbankan "Pembangunan" (AKBP) Padang \\ riairwan337@gmail.com
}

\begin{abstract}
The purpose of this research was coundoced to find out how credit management in an effort to increase liquidity on bank bank nagari padang. The research method used is the metohed of data qualitative descriptive.The kind of used data is secondary data obtained from the publication of the bank indonesia and the bank nagari padang period 2013 2017. The results of research shows that comparison level LDR banks are in the position of healthy, a comparison level NPL was still in a position to less healthy, and a comparison LAR also shows the bank has not been able to meet the demand of the credits. While the comparison of QR banks shows in a healthy position so that the bank is able to cover its obligations by using tools liquid owned by the bank.
\end{abstract}

Keywords :Liquidity,LDR,NPL,LAR,QR

\section{PENDAHULUAN}

Meningkatkan perkembangan perekonomian Indonesia, sangat tergantung pada perkembangan diberbagai tempat baik secara langsung maupun tidak langsung akan mempengaruhinya. Sektor perbankan menjadi Intermediary sistem dalam supporting bagi performance perekonomian baik di nasional maupun di daerah.

Daerah memiliki Bank Pembangunan sendiri untuk Sumatera Barat yaitu bank nagari sebagai salah satu usaha milik daerah. Memberikan pelayanan untuk kepuasan nasabah yang ada pada bank nagari bertujuan agar nasabah yang datang merasakan kenyamanan dalam keperluannya tentang apa yang diinginkan terhadap bank nagari.

Menurut Undang-Undang RI No.10 Tahun 1998, Bank merupakan suatu badan usaha yang melakukan penghimpunan dana dari masyarakat dalam bentuk simpanan dan menyalurkannya kembali dalam bentuk kredit atau bentuk lainnya dalam rangka meningkatkan taraf hidup rakyat banyak. Bagi masyarakat, kredit sangat di perlukan dalam mendukung dan mengembangkan usahanya, dimana dengan menggunakan dana kredit bisa untuk menambahkan atau meningkatkan berbagai faktor produksi baik berupa tambahan modal kerja, peningkatan sumber daya manusia dan lain sebagainya (Baiya \& Fernos, 2016).

Begitu pentingnya peran perbankan bagi suatu daerah maka bank nagari perlu meningkatkan kinerja keuangannya, dalam hal ini harus meningkatkan likuiditasnya. Disimpulkan bahwa usaha perbankan meliputi tiga kegiatan yaitu menghimpun dana, menyalurkan serta memberikan jasa lainnya. Penghimpunan dana meliputi giro, tabungan dan deposito, untuk menarik minat nasabah bank melakukan inovatif yang menarik seperti bungan dan pemberian hadiah, sebagai 
bentuk dorongan bagi masyarakat supaya lebih senang menabung, kegiatan penyaluran dana berupa pemberian pinjaman pada masyarakat. Dalam bentuk kredit yang berasal darimasyarakat berupa simpanantabungan serta deposito dan dana interna Bank Nagari cenderung lebih banyak dialokasikan kepada kegiatan kredit Bank Nagari. WilayahBank Nagari berpotensi terbatas padasuatu wilayah tertentu, Bank Nagari mengalami perkembangan karena mengarah pada kebutuhan atau kredit bagi masyarakat menengah kebawah yang memerlukan dana untuk pengembangan usaha ataupun konsumsi rumah tangga.

Menurut Anggraeni, Dkk (2014) likuiditas ialah masalah yang penting bagi pihak bank karenatingkat likuiditastinggi menunjukkan efisiensi tingkat kesehatanbank tersebut. Likuiditas mencerminkan usaha bankmemenuhi segala perantara dananasabah deposan, kewajibanyang sudah jatuhtempo dan memenuhi permintaankredit tanpapenundaan.

Melaksanakan pengelolaan kredit artinya menjalankan fungsi manajemen di mulai dari perencanaan, pengorganisasian, pelaksanaan dan pengawasan kredit. Fungsi ini dilaksanakan oleh manajemen kredit, yang secara luasnya manajemen kredit melaksanakan pengelolaan kredit dengan baik di mulai dari perencanaan jumlah kredit, penentuan suku bunga, prosedur pemberian kredit, analisis pemberian kredit hingga pengawasan serta pengendalian kredit yang macet.

Perlu dilaksanakan satu analisis yang dapat digunakan untuk mengetahui kekuatan serta kelemahan perusahaan dilihat dari laporan keuangan perusahaan tersebut. Alat yang dimaksud yaitu analisis laporan keuangan yang dapat dilakukan melalui analisis rasio keuangan perusahaan yang salah satunya mencakup rasio likuiditas.

Rasio Likuiditas dapat diukur melalui Quick Ratio, Loan to Deposit Ratio(LDR), Loan to Asset Ratio dan untuk menilai kualitas kredit dilihat dari Non Performing Loan (NPL) menurut Parathon, Dkk (2012). Perhitungan likuiditas ini untuk mengukur kinerja pada Bank Nagari menyalurkan dananya dan likuiditas dimana bank mampu memenuhi kewajiban jangka pendek berkaitan dengan dana yang dimiliki. Jika pemberian kredit yang melebihi batas dapat mengakibatkan resiko yaitu muncul tanda terjadinya kredit kurang lancar, diragukan dan macet, yang di hitung saat menentukan NPL (Non Perfoming Loan). Timbulnya tanda kredit kurang lancar, diragukan dan macet disebabkan masyarakat tidak bisa mengembalikan dana yang dipinjam tepat waktu. Hal ini bisa mengakibatkan kinerja likuiditas dan operasi Bank terganggu.

Secara akuntansi perbankan, pengukuran likuiditas dilakukan dengan perhitungan rasio yang menggambarkan hubungan timbal balik antara assets dan liabilities diwakili oleh nilai Loan to Deposit Ratio (LDR). Loan to Deposit Ratio Pada Bank Nagari Padang, sesuai dengan ketentuan BI dapat dinyatakan sehat antara 80\% - 100\%. Dilihat dari periode 2013 sampai dengan 2015 mengalami kenaikan atau baik, sedangkan pada periode 2016 dan 2017 mengalami penurunan.

Kinerja keuangan berikutnya dilihat dari nilai Loan to Asset Ratio Pada Bank Nagari Padang periode 2013 sampai dengan 2017 bank mampu menunjukkan kemampuan bank memenuhi permintaan kredit melalui sejumlah jaminan harta yang dimilikinya ialah dalam kondisi normal atau sehat. 
Kinerja keuangan berikutnya dilihat dari nilai Quick Ratio Pada Bank Nagari Padang untuk periode 2013sampai 2015 mengalami peningkatan yang signifikan, sedangkan periode 2016 dan 2017 mengalami penurunan tetapi masih berada pada ketentuan yang ditetapkan oleh BI. Bank nagari mampu dalam membayar kewajibannya dengan menggunakan alat likuid yang dimiliki oleh bank. Hal ini baik bagi bank, karena QR berada di atas 100\%. Dapat ditarik kesimpulan dalam setiap periode berada diatas standar yang telah ditetapkan BI. Hal ini membuktikan Bank Nagari padang dalam keadaan likuid jika dilihat dari segi QR, karena bank mampu menutupi kewajibannya dengan menggunakan alat likuid bank.

Dilihat dari nilai Non Performing Loan Pada Bank Nagari Padang terlihat bahwa tingkat kesehatan bank nagari padang dari tahun 2013 sampai dengan 2017 masih tetap rendah, karena berada dibawah 5\% yang telah ditetapkan BI.

Hal ini dapat digambarkan dalam beberapa indikator rasio keuangan seperti NPL cenderung mengalami penurunan bahkan tahun 2017 mendekati 5\% meskipun indikator LDR cenderung meningkat tiap periodenya. Disisi lain Quick Ratio bank nagari padang tergolong rendah, tetapi rendahnya nilai $\mathrm{QR}$ ialah kebijakan yang di ambil bank agar tidak terjadi idle fund untuk dana yang di tempatkan dan Loan to Asset menunjukkan nilai yang sehat atau kemampuan bank membayar kewajibannya segera tercukupi.

Berdasarkan uraian tersebut, maka tujuan penelitian ini yaitu untuk mengetahui bagaimana pengelolaan kredit dalam upaya meningkatkan likuiditas pada bank nagari padang.

\section{METODE PENELITIAN}

Dalam penelitian ini penulis menggunakan analisis data kualitatif dimana penelitian ini menjelaskan secara mengenai pengelolaan kredit dalam meningkatkan likuiditas pada Bank Nagari Padang.

\section{HASIL DAN PEMBAHASAN}

Perkembangan likuiditas bank nagari dapat tercermin dari Laporan Keuangan yang juga sekaligus meningkatkan kinerja keuangan bank nagari pada penelitian ini diambil periode 2013 sampai dengan 2017.

Likuiditas Bank Nagari dapat terlihat dari nilai Quick Ratio, Loan to Deposit Ratio (LDR), Loan to Asset Ratio dan Non Performing Loan (NPL). 
Tabel1

Nilai Likuiditas Pada Bank Nagari Periode 2013 - 2017

\begin{tabular}{|c|c|c|c|c|}
\hline Tahun & $\begin{array}{c}\text { NPL } \\
(\%)\end{array}$ & $\begin{array}{c}\text { LDR } \\
(\%)\end{array}$ & $\begin{array}{c}\text { QR } \\
(\%)\end{array}$ & $\begin{array}{c}\text { LAR } \\
(\%)\end{array}$ \\
\hline $\mathbf{2 0 1 3}$ & 3,1 & 83,16 & 118 & 68,30 \\
\hline $\mathbf{2 0 1 4}$ & 2,6 & 82,92 & 122 & 68,17 \\
\hline $\mathbf{2 0 1 5}$ & 2,5 & 82,17 & 122 & 67,92 \\
\hline $\mathbf{2 0 1 6}$ & 2,6 & 82,61 & 105 & 67,83 \\
\hline $\mathbf{2 0 1 7}$ & 3,0 & 82,65 & 106 & 69,41 \\
\hline
\end{tabular}

Sumber : Bank Nagari Padang, Data Diolah

Berdasarkan pada table 1 diatas dapat dijelaskan sebagai berikut :

a. Nilai Non Performing Loan

Pada Bank Nagari Padang tahun 2013 sampai 2017 tingkat NPL yang diperoleh bank cukup baik dan masih dalam batas aman sesuai peraturan Bank Indonesia. Dimana dari tahun 3013 sampai 2014 nilai NPL turun sebesar 19,35\% nilai ini terus mengalami penurunan sampai 2015 menjadi $8 \%$, hal ini menunjukkan semakin terkendalinya kredit bermasalah atau macet. Walaupun pada tahun 2016 nilai ini mengalami peningkatan namun pada angka yang tipis yaitu sebesar 3,7\% pada tahun 2016, namun menuju tahun 2017 angka ini mengalami peningkatan sebesar 2,07\%.

Secara keseluruhan walaupum di dua tahun ini mengalami peningkatan namun masih terkendali, ini membuktikan bank nagari padang mampu meminit dan meningkat secara relatif nilai kredit bermasalah. Berdasarkan surat edaran BI No.6/23/DPNP pada tanggal 31 mei 2004 dikatakan bahwa suatu bank dapat dikatakan sehat jika tingkat NPL kecil dari $5 \%$.

b. Nilai Loan to Deposit Ratio

Pada Bank Nagari Padang tahun 2013 sampai 2017 tingkat NPL yang diperoleh bank cukup baik dan masih dalam batas aman sesuai peraturan Bank Indonesia. Dimana dari tahun 3013 sampai 2014 nilai LDR turun sebesar 1,48\% nilai ini sedikit mengalami peningkatan di tahun 2015 sebesar 0,29\%\%, hal ini menunjukkan semakin terkendalinya kredit bermasalah atau macet. Walaupun pada tahun 2016 nilai ini mengalami peningkatan namun pada angka yang tipis yaitu sebesar $0,53 \%$ pada tahun 2016 , namun menuju tahun 2017 angka ini mengalami peningkatan sebesar $0,05 \%$.

\section{c. Quick Ratio}

Pada Bank Nagari Padang tahun 2013 sampai 2017 tingkat Quick Ratio yang diperoleh bank cukup baik dan masuh dalam batas aman sesuai dengan peraturan Bank Indonesia. Dimana dari tahun 2013 samapi 2014 nilai QR naik menjadi 3,39\%, pada tahun 2015 nilai QR sama dengan tahun 2014. Nilai ini mengalami penurunan pada tahun 2016 menjadi 13,93\%, pada tahun 2017 mulai mengalami peningkatan kembali sebesar 0,95\%. 


\section{d. Loan to Asset Ratio}

Pada Bank Nagari Padang tahun 2013 sampai 2017 tingkat Loan to Asset Ratio yang diperoleh bank cukup baik dan masuh dalam batas aman sesuai dengan peraturan Bank Indonesia. Dimana dari tahun 2013 samapi 2014 nilai LAR menurun menjadi 0,19\%, pada tahun 2015 nilai LAR masih mengalami penurunan sebesar 0,37\%. Walaupun pada tahun 2016 masih mengalami penurunan namun pada angka yang tipis yaitu sebesar $0,13 \%$. Pada tahun 2017 mulai mengalami peningkatan kembali sebesar 2,33\%.

\section{SIMPULAN}

Berdasarkan hasil pengelolaan kredit pada bab sebelumnya, dapat di ambil kesimpulan sebagai berikut :

a. Tingkat Non Performing Loans pada Bank Nagari Padang dari Tahun 20132017 mengalami turun naik dari tahun yang mana hal tersebut masih tergolong baik karena masih berada dibawah standar ketentuan Bank Indoneia yaitu sebesar 5\%. Dengn total kredit yang mengalami peningktan setiap tahunnya. Faktor-fator yang mempengaruhi naik turunnya total kredit diantaranya adalah kemauan dari para debitur, kondisi perekonomian Indonesia dan juga kebijakan dari pemerintah. Sebagaimana fungsi bank yaitu untuk menghimpun dana dan menyalurkannya kembali. Untuk memaksimalkan hal ini agartetapterkoordinirdengan baik, makapihakbank memangharusmembuatsistem manajemen pada berbagai aspek dan pihak yang terlibat. Langkah ini merupakan upaya yangcukupbagus dalammelakukan manajemenkegiatanoperasional bak, diantaranyaadalahuntuk mengurangi resiko gagalkreditatau kreditmacet yangakhirnya bisamenghasilkan tingkat atau totalkredityang terusmeningkatdengan baik.

b. ditarik kesimpulan bahwa bank nagari padang mampu membayar kembali penarikan dana yang dilakukan oleh nasabah dengan mnggunakan kredit yang diberikan bank dengan dana yang diterima oleh bank. Hal ini dibuktikan dengan menghitung LDR, bahwa setiap periodenya bank berada pada batas dibawah 94,75\% yang artinya tingkat likuiditas bank adalah sehat. Untuk itu bank perlu menjaga tingkat likuiditasnya, dengan cara menyediakan dana sesuai dengan kebutuhan dan sisanya bank dapat menggunakan dana tersebut melalui penyaluran kredit, agar terhindar dari idle money dimana dana yang ada dalam bank banyak yang menganggur

c. Quick Ratio pada Bank Nagari Padang Dari analisis diatas, dapat ditarik kesimpulan bahwa hasil QR dalam setiap periode berada diatas standar yang telah ditetapkan yaitu diatas $100 \%$. Hal ini membuktikan bahwa bank nagari padang dalam keadaan likuid jika dilihat dari segi QR, karena bank mampu menutupi kewajibannya dengan menggunakan alat likuid bank. Namun, jika dilihat pada periode 2013 - 2017 QR bank terlalu tinggi, sehingga dari segi pengelolaan dananya, bank memiliki asset lancar terlalu banyak sehingga dapat menimbulkan idel money atau dana menganggur. Hal ini tentunya tidak baik bagi bank.Untuk itu bank dapat menyediakan asset sesuai dengan kebutuhan dan sisanya bank dapat menyalurkan asset tersebut melalui pemberian kredit kepada nasabah. 
d. Loan to Asset Ratio Pada Bank Nagari Padang menunjukkanbahwadalam kemampuanbankmemenuhi permintaankreditmelaluisejumlahjaminanharta yangdimilikinyaadalah dalam kondisi normal atau sehat.

\section{UCAPAN TERIMA KASIH}

Terimakasih penulis sampaikan kepada :

1. Kedua Orang Tua yang senantiasa untuk memberi dukungan baik secara moril maupun materil.

2. Direktur AKBP beserta prodi AKBP yang telah memberikan kesempatan untuk penulis dapat melakukan penelitian ini.

3. Dosen Pembimbing Tugas Akhir yang telah memberi arahan dan bimbingan hingga tugas akhir ini bisSa terselesaikan.

4. Pimpinan Bank Nagari Padang yang telah mengizinkan penulis dalam memperoleh informasi beserta pengambilan data.

5. Semua Pihak yang telah memberikan dukungan dan bantuannya dalam penyelesaian tugas akhir ini.

\section{DAFTAR PUSTAKA}

Anggraeni, R. K., \& Dkk. (2014). Analisis Pengelolaan Kredit Untuk Meningkatkan Likuiditas dan Profitabilitas PT BPR Wlingi Pahala Pakto. Jurnal Administrasi Bisnis, 12(2), 1-10.

Andriani, B., \& Susanto, R. (2019). Pengawasan Kredit PT. Bank Perkreditan Rakyat (BPR) Ophir Pasaman Barat. https://doi.org/10.31219/osf.io/aunvc

Amelia, L., \& Marlius, D. (2018). Pengendalian Kredit Dalam Upaya Menciptakan Bank Yang Sehat Pada PT. Bank Pembangunan Daerah Sumatera Barat Cabang Utama Padang. https://doi.org/10.31227/osf.io/kpc64

Alanshari, F., \& Marlius, D. (2018). Prosedur Pemberian Kredit KPR Pada PT. Bank Tabungan Negara (Persero) TBK Cabang Pembantu Bukittinggi. https://doi.org/10.31227/osf.io/rsfhc

Baiya, \& Fernos, J. (2016). Analisis faktor-faktor Penyebab Kredit Macet Pada Bank Nagari Cabang Siteba. Akademi Keuangan Dan Perbankan "Pembangunan," 1-18.

Parathon, A. A., Dzulkirom, \& Farah, D. (2012). Analisis rasio keuangan perbankan sebagai alat ukur kinerja keuangan bank. Student E-Journal UB, $1-11$.

Prasanjaya, Y., \& Ramantha, W. (2013). Analisis Pengaruh Rasio CAR, BOPO, LDR dan Ukuran Perusahaan Terhadap Profitabilitas Bank Yang Terdaftar di BEI. E-Jurnal Akuntansi Universitas Udayana, 1(4), 230-245. 
Purwanto, A. J. (2014). Pentingnya Mempelajari Teori Organisasi. Teori Organisasi, 1-51.

Susanto, H., \& Kholis, N. (2016). Analisis Rasio Keuangan Terhadap Profitabilitas Pada Perbankan Indonesia. Jurnal Ebbank, 7(1), 11-22.

Tanor, M. O. (2015). Analisis Laporan Keuangan Dalam Mengukur Kinerja Keuangan Pada PT. Bank Artha Graha Internasional, Tbk. 3(3), 639-649.

Undang-Undang RI No.10. (1998). Undang-Undang Republik Indonesia No.10 Tahun 1998 Tentang Perubahan Atas Undang-Undang No.7 Tahun 1992 Tentang Perbankan.

Winardi, J. Teori Organisasi \& Pengorganisasian, Teori Organisasi \& Pengorganisasian 1-20 (2006). Jakarta: PT. Rajagrafindo Persada. https://doi.org/10.1302/0301-620X.93B1.24767

Widayati, R. (2019). Penyelesaian Kredit Bermasalah Pada PT. Bank Perkreditan Rakyat (BPR) Nagari Kasang. https://doi.org/10.17605/OSF.IO/D4MF3

Widayati, R. (2019). Pelaksanaan Prinsip Kehati-Hatian Dalam Pemberian Kredit Konsumtif Pada Bank Nagari Cabang Siteba. https://doi.org/10.17605/OSF.IO/FZVXR

Widayati, R. (2019). Aktivitas Pemberian Kredit Komersil Pada Bank Nagari Cabang Sijunjung. https://doi.org/10.17605/OSF.IO/QTVZ9

Widayati, R. (2019). Pelaksanaan Kredit Pada Bank Perkreditan Rakyat LPN Pasar Baru Durian Sawahlunto. https://doi.org/10.17605/OSF.IO/5HPAB

Widayati, R. (2019). Upaya Penanganan Kredit Bermasalah Pada Bank Nagari Cabang Utama Padang. https://doi.org/10.17605/OSF.IO/YJ3KN

Widayati, R. (2019). Aktivitas Pemberian Kredit Usaha Pada PT. Bank Perkreditan Rakyat Batang Kapas. https://doi.org/10.17605/OSF.IO/EDPN4 